\title{
Distributed Agency: Foreign Policy sans MFA
}

\author{
Jason Dittmer \\ University College London, London, United Kingdom \\ j.dittmer@ucl.ac.uk
}

Received: 9 September 2019; revised: 14 September 2019; accepted: 10 October 2019

\section{Summary}

This short provocation argues for a diplomacy studies that is less focused on the rationality of states, with the ministry of foreign affairs (MFA) as an imagined black box in which calculation occurs, and more on the idea of 'external' agency as the emergent effect from a range of elements within and without the state. To illustrate this idea, the essay sketches out an example of foreign policy made in the absence of an MFA entirely: Gibraltar's 2019 intervention in the Grace 1 controversy.

\section{Keywords}

Gibraltar - paradiplomacy - assemblage theory - Grace 1 - Iran - Overseas Territories

\section{$1 \quad$ Introduction}

The foundational myth of the ministry of foreign affairs (MFA) is its imagined role as a black box in which the state determines its interests in the external realm and selects strategies through which to enact them. ${ }^{1}$ This foundational myth is rooted in the traditional theoretical concerns of international relations (IR), which have fostered the assumption of rational states as autonomous actors in an anarchic world. Of course, work in IR and particularly in the interdisciplinary field of diplomacy studies has done much to complicate this account, highlighting the more-than-rational nature of diplomacy as actually

1 Müller 2012, 379 . 
practiced by human beings, ${ }^{2}$ and also the diplomatic agency of cities, regions, non-governmental agencies, diasporas, religions, and other non-state actors. ${ }^{3}$ Nevertheless, it is because of the foundational myth that so many scholars have taken MFAs as an object of study, seeing them as a medium through which to examine the changing international system during a period of technopolitical transformation. ${ }^{4}$ This approach, often adopting the language of organisation studies and related fields, is interesting in that it points to the ways in which the MFA is multiply enmeshed. It is part of the larger state apparatus, and also part of the larger diplomatic system; buffeted by forces at work in both of these organisational ecosystems, the MFA can be seen less as an all-powerful agent of world politics and more like a tail being wagged by two different dogs. This short essay argues for an approach to MFAs that - paradoxically — decentres MFAs. It does so by advocating for an assemblage approach to diplomacy studies and international relations, an approach the author has written about extensively elsewhere, and which only briefly recaps here. ${ }^{5}$ Here, he goes further by discussing how assemblage helps us to consider paradiplomacy (and other non-state diplomacies) by actors who lack an MFA entirely. He does so via a discussion of the 2019 Grace 1 incident in Gibraltar, in which an Iranian oil tanker was interned by the Gibraltarian authorities. This essay's argument is that - at least in this case - we can see a distributed assemblage of foreign policy actors throughout multiple polities, collectively working towards coherence and agency.

\section{$2 \quad$ Diplomatic Assemblages}

Assemblage theory refers to a wide range of Deleuzean-inspired theorisations of sociomaterial processes. It has a number of advantages for thinking about diplomacy and international relations, partly because of how obviously parallel its ontology is (i.e., it is fundamentally about relations) but also because of how it calls our attention to aspects of diplomacy that are generally neglected (materiality and the role of affect, for instance).

2 Neumann 2002, 629; Pouliot and Cornut 2015, 298.

3 Leffel 2018; Henders and Young 2016; Nganje 2014; Acuto 2013; Cornago 2010; McConnell, Moreau and Dittmer 2012.

4 Hocking and Spence 2002; Hocking 2005; Moses and Knutsen 2001; Rana and Kurbalija 2007; Georgiadou 2013.

5 Dittmer 2017. 
Martin Müller surveys the literature on assemblages and asserts that there are five common characteristics of assemblages. ${ }^{6}$ First, assemblages are defined by relations of exteriority that form between constituent elements, and these relations mean that the whole exceeds the sum of the parts. That is, parts of the MFA are simultaneously parts of other assemblages, and these provide points of contact. One might think of an Ambassador, who is simultaneously part of the MFA assemblage and of the diplomatic corps where he or she is posted. This means that individual bodies serve as conduits between distinct assemblages, allowing affects to circulate and producing change. Indeed, Müller's second point is that assemblages are constantly becoming otherwise, with some constituent elements coming, going, and undergoing change all the time. This is clear at shorter temporalities, with staff coming and going from the building according to the rhythms of the 'daily grind', at the medium temporality with staff being trained and therefore transformed by their enmeshing in the bureaucracy, ${ }^{7}$ and at longer temporalities where we see cohorts and other generational shifts in the institution over time. ${ }^{8}$ Third, assemblages are heterogeneous; they are likely to be composed of a variety of bodies, objects and energies. For instance, in the author's previous work he called attention to the role of paper as a connective technology linking together embassies and MFAs in the 19th century. However, rather than some dematerialised abstract communication, this paper had volume and mass that materially impacted the workings of the British Foreign Office and the design of the new office. ${ }^{9}$ Fourth, because they are composed of elements that are externally oriented, assemblages are impossible to definitively delimit. For this reason, assemblage thinking involves an ecological approach rather than one of delimitation and stabilisation. For the purposes of this essay, 'no MFA is an island'; hence, the aforementioned interest by scholars in the MFA as a way into the topic of the overall diplomatic system. Finally, assemblages are potentially self-organising, tending towards expansion of their agencies without intent. We might see a parallel here in the well-known tendency of bureaucracies to expand in terms of ambition and resource needs. This is here conceptualised as a form of desire, or a will to power. In short, the turn to Gilles Deleuze and assemblage adds a register beyond power relations; the world is full of material forces that shape the ground on which international relations rest.

\footnotetext{
6 Müller 2015, 28-29.

7 Kuus 2016, 41-42.

8 Otte 2011, 17 .

9 Dittmer 2016, 8o.
} 
What does all this mean for diplomacy? This essay argues that it posits a flat ontology for diplomatic studies, in which the MFA (or the state more broadly) is not 'above' individuals in a scalar sense but instead is an emergent agency that is performed into existence by ongoing relations among people, objects and energies. That much has been conceptualised before. ${ }^{10}$ Assemblage indicates, however, that elements engaged in an assemblage are changed in some way by that participation. The key concept here is affect, or the difference that being in relation makes. This can be a physical change of state; Manuel DeLanda gives the example of bringing a lit candle and a stick of butter into relation. The butter's melting is an affect of their relationship of proximity. ${ }^{11}$ In this essay, however, we can think of affect as the way in which being in relation shapes political subjectivities. Recall, for instance, the above example of how people in an MFA are trained, and therefore shaped, by institutionalisation.

But this essay goes further, highlighting that diplomacy indicates the formation of relations that connect MFAs, allowing affects to circulate between them and thereby opening up the potential for altered political subjectivities among all those participating. Here, then, is a potential point of contact with the larger literature on diplomatic cultures and international society. ${ }^{12}$ But more crucially, it points to how the MFA indeed is not a black box; instead, it always is already enmeshed in the world of affects that it seeks to control. That is, each state's collective political subjectivity is constantly emergent from the seething, pulsing affects of the wider diplomatic sphere. ${ }^{13}$

So far, so good. But what does assemblage thought do for our understanding of polities - like Gibraltar — that do not have an MFA? As a British Overseas Territory, Gibraltar is a polity that (since its 2006 Constitution) has control over virtually every aspect of its own politics, except foreign affairs and defence. These remain the prerogative of the United Kingdom, represented in Gibraltar by the Governor. Nevertheless, because of ongoing contestation of Gibraltar's right to self-determination by the Spanish government, and more recently because of the need to deal with Brexit negotiations, Gibraltar has a history of representing itself in international forums such as the UN and the European Union (EU), despite having no dedicated MFA. By examining the Grace 1 incident, this essay highlights how foreign policy emerges out of a virtual MFA, distributed across multiple polities.

\footnotetext{
$10 \quad$ Mitchell 1991, 89.

11 DeLanda 2006, 33.

12 Bull 1977, 304; Sharp 2009, 11; Dittmer and McConnell 2016, 105.

13 Dittmer 2017, 8-9.
} 
The Grace 1 was a Panamanian-flagged oil tanker seized by British Royal Marines on 4 July 2019 when it entered Gibraltarian territorial waters. This seizure was justified by EU sanctions on Syria, as the Grace 1 was involved in bringing Iranian oil to the Syrian regime (at the time of this writing, Gibraltar and the UK are still part of the EU). Indeed, Panama had revoked its registration of the vessel over a month earlier because the ship was believed to be implicated in the breaking of sanctions. ${ }^{14}$ Gibraltar released the ship on 15 August 2019 with a promise from the Iranians that the ship — now Iranian-flagged and renamed the Adrian Darya 1 — would not deliver the oil to Syria. However, it is widely believed that the oil did eventually make its way to Syria, and that the release of the Adrian Darya 1 was agreed by the Gibraltarian authorities despite a US warrant for its detention - as a quid pro quo for a British-flagged tanker that had been subsequently detained by the Iranians in the Straits of Hormuz (the Stena Imperio). ${ }^{15}$

The incident is likely to remain a footnote in the long, contentious history of UK-Iranian diplomacy. However, what makes it interesting here is the agency afforded to HM Government of Gibraltar in the media accounts of the Grace i's seizure. Indeed, the role of the UK government - outside the provision of the Royal Marines, who were flown in from England for the operation - is backgrounded to an astonishing degree, with 'Gibraltar port and law enforcement agencies detain[ing] the super tanker and its cargo ... with the help of the marines' and Gibraltar's Chief Minister Fabian Picardo subsequently writing 'to the presidents of the European Commission and European Council to give details of the sanctions that have been enforced'. The attribution of agency was complete when 'a spokesman for Prime Minister Theresa May said she welcomed the "firm action" by the Gibraltarian authorities.'16 Given that Gibraltar has no constitutional competency for foreign affairs or defence, and no MFA, how are we to make sense of this?

The quickest answer - which undoubtedly has some truth to it - is that the UK saw advantage in this formulation. It avoided the 'colonial' implications of acting through its Overseas Territories, for which the UK is frequently criticised at the United Nations, and gave the UK some plausible deniability given the delicate politics of the US-abandoned nuclear deal. However, in an interview conducted by the author during the crisis (23 July 2019), Gibraltarian Deputy

\footnotetext{
14 Merkel 2019.

15 See 'Iran Oil Tanker: Gibraltar Orders Release of Grace 1' 2019.

16 This and previous, 'Oil Tanker Bound for Syria Detained in Gibraltar' 2019.
} 
Chief Minister Joseph Garcia indicates an altogether more complicated picture. He argues that the decision (to detain the Grace 1 ) was indeed a decision taken in Gibraltar. While the Chief Minister was the key decision-maker, the issue was taken up several times by the Gibraltar Contingency Council (GCC), which is jointly chaired by the Governor and the Chief Minister and includes elected officials from HM Government of Gibraltar as well as the Commissioner of Police and the Commander of British Forces in Gibraltar. The GCC combined two previously distinct committees, the Gibraltar Security Council (focused on external security threats) and the Civil Contingencies Committee (focused on domestic crises). "The revised structure acknowledges that civil emergencies and security threats can easily overlap, requiring the Gibraltar Government and the Governor to be in a position to fulfil their respective constitutional roles swiftly and effectively' ${ }^{\prime 7}$ In short, the practical advantages of linking up parts of Gibraltar governance during a crisis inspired this 2016 reform, which has muddied the constitutional distinction between defence/security and domestic matters. So, the decision to stop the Grace 1 emerged out of an administrative context that blurred the boundaries between the Gibraltarian and UK polities. Garcia reports that the intelligence about the Grace 1 came from the UK (although it ultimately probably originated in the United States), ${ }^{18}$ as did the Royal Marines that composed the boarding party. This administrative hybridity is paralleled by the legal framework in which Gibraltar undertook the operation, which was based on EU sanctions that had been agreed by the EU Council (including the UK). And yet the final decision ultimately remained in Gibraltarian hands. In the words of Garcia, 'I think the decision to act or not to act, and the decision by the police to request military assistance to enforce EU sanctions ..., were decisions taken here, after discussion and engagement'. ${ }^{19}$

This situation, however, is part of a broader effort by Gibraltar to represent itself, as described above. Indeed, Gibraltar regularly represents itself in London, Brussels, New York (the UN), and Washington, DC. This is primarily undertaken by the Chief Minister and the Deputy Chief Minister (who has the portfolio for Europe, and consequently for Brexit). Garcia reports that this representation does not run into conflict with UK diplomacy, in part because it is conducted in assemblage with the UK foreign policy apparatus. This does not mean that Gibraltar's interests are always the same as the UK's (as Brexit shows) but rather that many of the material assets that enable Gibraltar to represent itself are formally part of the British state (like the intelligence

17 Reyes 2016.

18 Dittmer 2015, 6o9-61o.

19 Joseph Garcia, Gibraltarian Deputy Chief Minister, interviewed by the author, 23 July 2019. 
assets that produced the Grace 1 incident). Consequently, the external agency of Gibraltar is affected by the UK foreign policy apparatus, and vice versa. Whenever a Gibraltarian delegation goes to Washington or New York, they always meet with the British Ambassador to coordinate their action. Again according to Garcia, 'We work together with the UK assets, and they have more assets. And I think even though we're quite small we do punch above our weight'. The focus on 'material assets' in this description of Gibraltarian agency recalls the shared materials of assemblage, which allow affects to circulate and agencies to emerge. ${ }^{20}$

Of course, until Brexit finally happens, the UK is also enmeshed in the European External Action Service (EEAS), which itself affects British foreign policy making. ${ }^{21}$ For many Member States, the EEAs has enhanced its diplomatic presence around the world through the pooled resources of the EU (although the UK has availed of this less than have other Member States). ${ }^{22}$ Indeed, it is the larger EU context of sanctions that justified the Grace 1 incident, and the British context of intelligence and military force that enabled the vessel to be halted. Crucially though, it is the postcolonial context of Gibraltar that led to the ultimate decision being located with the Chief Minister of a government presiding over a mere 34,000 people. We can therefore start to conceptualise the virtual MFA of Gibraltar as a kind of distributed agency, enmeshed multiply in the UK foreign policy apparatus and the EU's EEAS, and emergent from the complex interactions of all its elements.

Gibraltar is, of course, a pretty unusual case. Critics might dismiss this mini case study as the exception that proves the rule. Other parallel contexts, however, come to mind: most obviously, the European External Action Service which coordinates Member State agencies but is also a lever for those Member States' agencies to pull. We might also consider the realm of social media, which increasingly fragments the voice of the MFA as individual personalities air their views, with algorithms prioritising some voices over others. However, more radically, the Grace 1 points us to a different way of thinking about diplomacy one that displaces the MFA and the assumption of a rational state that has ensconced it at the centre of diplomacy. Instead, this essay posits a world of

\footnotetext{
20 Garcia interview.

21 Dittmer 2017, 106.

22 Bachmann 2016, 3.
} 
forces acting on and through a range of human and non-human actors, producing political subjects who act, or are seen to act, in the international realm. MFAs are, of course, part of that world of forces and, indeed, many of the political subjects in whom diplomacy studies scholars are interested can be found within their walls. However, they are not a black box; rather they are fully open to the outside world, and we should study all the relations - diplomatic or otherwise - that enable diplomatic agency to appear in the world.

\section{Bibliography}

Acuto, Michele. 'World Politics by Other Means? London, City Diplomacy and the Olympics'. The Hague Journal of Diplomacy 8 (3-4) (2013), 287-311.

Bachmann, Veit. European External Action: The Making of EU Diplomacy in Kenya (London: Routledge, 2016).

Bull, Hedley. The Anarchical Society: A Study of Order in World Politics (London: Macmillan, 1977).

Cornago, Noé. 'On the Normalization of Sub-State Diplomacy'. The Hague Journal of Diplomacy 5 (1-2) (2010), 11-36.

DeLanda, Manuel. A New Philosophy of Society: Assemblage Theory and Social Complexity (London: Continuum, 2006).

Dittmer, Jason. 'Everyday Diplomacy: UKUSA Intelligence Cooperation and Geopolitical Assemblages'. Annals of the Association of American Geographers 105 (3) (2015), 604-619.

Dittmer, Jason. 'Theorising a More-than-Human Diplomacy: Assembling the British Foreign Office, 1839-1874'. The Hague Journal of Diplomacy 11 (1) (2016), 78-104.

Dittmer, Jason. Diplomatic Material: Affect, Assemblage and Foreign Policy (Durham: Duke University Press, 2017).

Dittmer, Jason and Fiona McConnell. 'Diplomatic Cultures'. In The SAGE Handbook of Diplomacy, eds. Costas Constantinou, Paul Sharp and Pauline Kerr (London: SAGE, 2016), 104-113.

Georgiadou, Elena. 'The Greek Ministry of Foreign Affairs in the Transforming World Politics: Between Isomorphism and Path Dependence'. The Hague Journal of Diplomacy 8 (2) (2013), 139-160.

Henders, Susan and Mary Young. "Other Diplomacies" of Non-State Actors: The Case of Canadian-Asian Relations'. The Hague Journal of Diplomacy 11 (4) (2016), 331-350.

Hocking, Brian, ed. Foreign Ministries: Change and Adaptation, 2nd ed. (New York: Palgrave Macmillan, 2005). 
Hocking, Brian and David Spence, eds. Foreign Ministries in the EU: Integrating Diplomats (Houndmills: Palgrave Macmillan, 2002).

Kuus, Merje. 'Diplomacy and Audit: Technologies of Knowledge in Europe'. Geoforum 68 (1) (2016), 39-47.

'Iran Oil Tanker: Gibraltar Orders Release of Grace 1'. BBC News, 15 August 2019. https:// www.bbc.co.uk/news/uk-49362182.

Leffel, Benjamin. 'Animus of the Underling: Theorizing City Diplomacy in a World Society'. The Hague Journal of Diplomacy 13 (4) (2018), 502-522.

McConnell, Fiona, Terri Moreau and Jason Dittmer. 'Mimicking State Diplomacy: The Legitimizing Strategies of Unofficial Diplomacies'. Geoforum 43 (4) (2012), 804-814.

Merkel, Dana. 'U.S. Power to Seize Oiler Grace 1, Now under Iranian Flag, Is Limited by International Law'. USNI News, 29 August 2019. https://news.usni.org/2019/o8/29/ u-s-power-to-seize-oiler-grace-1-now-under-iranian-flag-is-limited-by-inter national-law.

Mitchell, Timothy. 'The Limits of the State: Beyond Statist Approaches and Their Critics'. American Political Science Review 85 (1) (1991), 77-96.

Moses, Jonathan and Torbjørn Knutsen. 'Inside out: Globalization and the Reorganization of Foreign Affairs Ministries'. Cooperation and Conflict 36 (4) (2001), 355-380.

Müller, Martin. 'Opening the Black Box of the Organization: Socio-Material Practices of Geopolitical Ordering'. Political Geography 31 (6) (2012), 379-388.

Müller, Martin. 'Assemblages and Actor-Networks: Rethinking Socio-Material Power, Politics and Space'. Geography Compass 9 (1) (2015), 27-41.

Neumann, Iver. 'Returning Practice to the Linguistic Turn: The Case of Diplomacy'. Millennium:Journal of International Studies 31 (3) (2002), 627-651.

Nganje, Fritz. 'The Developmental Paradiplomacy of South African Provinces: Context, Scope and the Challenge of Coordination'. The Hague Journal of Diplomacy 9 (2) (2014), 119-149.

'Oil Tanker Bound for Syria Detained in Gibraltar'. BBC News, 4 July 2019a. https://www .bbc.co.uk/news/uk-4886503o.

Otte, T.G. The Foreign Office Mind: The Making of British Foreign Policy, 1865-1914 (Cambridge: Cambridge University Press, 2011).

Pouliot, Vincent and Jérémie Cornut. 'Practice Theory and the Study of Diplomacy: A Research Agenda'. Cooperation and Conflict 50 (3) (2015), 297-315.

Rana, Kishanv and Jovan Kurbalija, eds. Foreign Ministries: Managing Diplomatic Networks and Optimizing Value (Valetta: DiploFoundation, 2007).

Reyes, Brian. 'New Structure Enhances Rock's Response to Security Threats and Emergencies'. Gibraltar Chronicle, 5 December 2016. https://www.chronicle.gi/ new-structure-enhances-rocks-response-to-security-threats-and-emergencies/. 
Sharp, Paul. Diplomatic Theory of International Relations (Cambridge: Cambridge University Press, 2009).

\section{Jason Dittmer}

is Professor of Political Geography at University College London. His 2017 book Diplomatic Material: Affect, Assemblage, and Foreign Policy was published by Duke University Press. He is Co-Editor of Diplomatic Cultures and International Politics: Translations, Spaces, and Alternatives published by Routledge in 2015. 